\title{
Mental disorder and driving
}

\author{
Andrew Lawrie and Steven Milne
}

\begin{abstract}
A one day census of patients on the acute wards at a psychiatric hospital revealed that approximately $40 \%$ of in-patients were holders of ditiving licences and that the majority of them would be affected by the current regulations regarding fitness for ditving. Desplite this, fow patients could recall being given medical advice regarding their ditving. In only one case was any advice documented in the case-notes. Psychiatrists' responsibility for ensuring that patients are given appropriate information regarding the effects of their illness or medication on their driving performance is discussed.
\end{abstract}

Medical disorders in general account for only a small proportion of road traffic accidents (Raffle, 1985). Nonetheless, psychiatrists need to be aware of the regulations regarding driving and mental disorder in order that they can furnish patients with appropriate advice. The Medical Commission on Accident Prevention (Raffle, 1985) has issued guidelines concerning medical aspects of fitness to drive. The Royal College of Psychiatrists (1981) has published a document on mental illness and vocational driving. Finally, the Driver and Vehicle Licensing Agency (DVLA a department of the Driving and Vehicle Licensing Centre (DVLC)) has produced an At a Glance Guide to the Current Medical Standards of Fitness to Drive (DVLA, 1993). All three documents are in general agreement although there are some differences in their recommendations.

It is important to realise that there are differences in the regulations pertaining to ordinary licence holders and vocational licence holders (holders of Heavy Goods Vehicle or Public Service Vehicle licences). The regulations for vocational drivers are more stringent. The DVLA advises that drivers holding ordinary licences should not drive for six to 12 months following recovery from an acute psychotic episode requiring hospital admission; for six months in the case of schizoaffective disorder requiring admission; for at least 12 months in cases of alcohol misuse or dependence whether or not requiring admission and for six to 12 months following use or dependency, or both, on illicit drugs. The diagnosis of personality disorder may result in revocation of the licence. In cases of dementia, an annual medical review is required and the licence is likely to be revoked, particularly if there is any disorientation. In all of the above cases, the
DVLC should be notified by the sufferer and re-issue of the licence would be subject to further review. Severe mental handicap constitutes a bar to applying for or holding a licence.

Any vocational driver who has been off work for more than 28 days as the result of mental disorder should be subject to medical examination and report (Royal College of Psychiatrists, 1981). For psychotic episodes, the DVLA recommends that patients should be symptom-free and not taking psychotropic medication (with the exception of lithium) for at least three years before returning to vocational driving. By contrast, the Royal College of Psychiatrists (1981) suggests that patients who have had manic illness should not drive vocationally for ten years. For vocational drivers suffering from serious, acute neurotic disorders, the DVLA states that patients should not drive for a six months symptom-free period after cessation of medication. However, driving may be permitted if the driver is maintained symptom-free on medication with no sideeffects likely to impair driving performance. The DVLA advocates that personality disorder associated with "behaviour disturbance likely to be a source of danger at the wheel" should result in revocation of the vocational licence. The Royal College of Psychiatrists report argues, however, that such cases can probably to best identified and dealt with by the judicial system. In cases of alcohol or illicit drug misuse, the DVLA declares that the vocational licence should be suspended for three years.

There is little known about the effects of mental disorder on driving. In one review (Silverstone, 1988), increased road accident rates were found in the elderly, benzodiazepine users and people with neurotic illnesses, personality disorders and depression. There was no evidence of increased accident rates in people with schizophrenia or mania. Many psychotropic drugs can cause drowsiness and thus affect driving, including major and minor tranquillisers, antidepressants and anti-muscarinics. Doctors are required to advise patients about the possible effects of medication on driving, although the decision to drive is left to the individual patient. While the effects of various drugs on psychomotor functioning is acknowledged, their influence on real driving performance, however, is less certain (Hindmarch, 1988). 
There is a paucity of information concerning the number of psychiatric patients who could be affected by the current guidelines. Similarly, little is known about the quality of information that mentally disordered patients currently receive with respect to driving. The present study aims to address these issues.

\section{The study}

A one-day census was undertaken of all patients on the acute wards at a local psychiatric hospital. Patients were given a self-report questionnaire asking about their current driving practice and about advice that they had received from their psychiatrist or general practitioner (GP). The case-notes of those patients completing the questionnaire were examined for basic demographic details, ICD-9 diagnosis, medication and documented advice regarding driving.

\section{Findings}

There were 67 people registered as in-patients on the day of the census. Twenty-one patients were on extended leave, three chose not to complete the questionnaires and one patient was too ill to co-operate. Of the $42(63 \%)$ patients completing the questionnaire, $23(55 \%)$ were male and 19 $(45 \%)$ were female. Twenty patients $(48 \%)$ had a diagnosis of schizophrenia, $12(29 \%)$ affective disorders, nine $(21 \%)$ neurotic illnesses or adjustment disorders and one had dementia. There were no significant differences between males and females with respect to age, length of stay or diagnosis.

Sixteen patients (38\%) held a driving licence at the time of the census. A further seven patients had held a licence in the past. There were no holders of vocational licences. There were no associations between licence holding and age, sex or diagnostic category (Mann-Whitney $P$ value of 0.91 and $\chi^{2} P$ values of 0.10 and 0.57 ). Thirty-six patients $(86 \%)$, including $12(75 \%)$ current licence holders, were being prescribed medication for which the British National Formulary advises caution with driving (BMA \& Royal Pharmaceutical Society of Great Britain, 1993).

Of patients who had ever held driving licences, ten (43.5\%) believed that their illness may influence their ability to drive, while $16(70 \%)$ thought that their medication could adversely affect their driving. Patients were asked if they had ever received advice from a doctor regarding the likely effects of their illness on driving. Six patients (26\%) stated that they had received advice from their GP. Only two patients $(9 \%)$ recalled receiving advice from their psychiatrist. Patients were then asked if they had ever received advice about the possible effects of medication on their driving. Seven patients $(30 \%)$ recalled receiving advice from their GP, nine (39\%) recalled receiving advice from their psychiatrist. Analysis of the case-notes revealed only one case where this advice was documented. This resulted from concerns raised about the patient driving as an in-patient.

\section{Comment}

Some of the results of this study must be viewed with caution in view of the small sample. For example, there may indeed be associations between licence holding and age, sex or diagnostic category which could not be demonstrated in this study due to insufficient numbers. Nevertheless, over half of psychiatric in-patients had held driving licences at some time and just under $40 \%$ were current licence holders. Most patients had diagnoses of psychotic or major affective illnesses and the majority were prescribed medication which could impair psychomotor performance. If these findings are applicable generally, it would appear that significant number of psychiatric in-patients are affected by regulations governing their fitness to drive.

It may be that patients find it difficult to recall advice that they are given about driving. Nevertheless, it was disconcerting to note that the majority of patients (over $90 \%$ ) reported receiving no information from psychiatrists about the consequences that their mental illness could have on their ability to hold a licence. Patients recalled receiving more advice from their GPs than from psychiatrists with regard to this matter. Only a third of patients reported receiving advice about the effects of medication. The finding that only one patient had such advice documented in their case-notes could have adverse medico-legal consequences. Although no vocational licence holders were identified in this study, doctors need to be aware of the different regulations affecting this group. This study was restricted to in-patients. One would forecast that a higher proportion of out-patients would be active drivers and the needs of this group also need to be addressed.

Psychiatrists have a responsibility to ensure that they give appropriate advice to patients on their ability to drive and that this advice is documented in case-notes. However, it is the duty of the driver to inform the DVLC if they "now have any physical or mental disability or condition which affects [their] fitness as a driver or which might do soon in the future" (health declaration on all driving licences). The DVLC may request medical reports before reaching a decision about a person's fitness to drive. In certain cases, however, psychiatric advice with regard to driving may be ignored by patients. In these circumstances, it may be appropriate to break 
that patient's confidence and inform the DVLC, if the doctor believes that an individual patient's mental disorder is likely to make his or her driving a source of danger to the public. It is recommended that doctors contemplating such a step should consult with their defence organisation before so doing.

\section{References}

Brttish Medical association \& Royal Pharmaceutical SOCIETY OF GREAT BRTtaIN (1993) British National Formulary. Number 25. London: Pharmaceutical Press.

DRIVER \& Vehicle LiCensing AGENCY (1993) At a Glance Guide to the Current Medical Standards of Fitness to Drlue. Swansea: DVLA.

HINDMARCH, L. (1988) A pharmacological profile of fluoxetine and other antidepressants on aspects of skilled per- formance and care handling ability. British Journal of Psychiatry. 163 (suppl. 3). 99-104.

RAFFLE. A. (Ed) (1985) Medical Aspects of Futness to Drive. London: The Medical Commission on Accident Prevention.

RoYal College of PSYchiatrists (1981) Psychiatric Disorders Contra-indicated for Drivers of Heavy Goods Vehicles (HGVs) and Public Service Vehicles (PSVs). London: Royal College of Psychiatrists.

SILVERSTONE, T. (1988) The influence of psychiatric disease and its treatment on driving performance. International Clinical Psychopharmacology, 3 (suppl. 1) 59-66.

Andrew Lawrie, Registrar; and *Steven Milne, Senior Registrar, St Nicholas Hospital, Jubilee Road, Gosforth, Newcastle upon Tyne NE3 3XT

*Correspondence

\title{
Do patients who have been on 'sections' get refused visas?
}

\author{
Danny Allen and Karen Allen
}

\begin{abstract}
A reason sometimes given for not applying a section of the Mental Health Act 1983 to patients for the first time is that this may stigmatise them in some way. A practical example of stigmatisation is that patients who have previously been 'sectioned' may be refused tourist or immigration visas to other countries. Since no information on this subject is avaliable in the psychiatric Iiferature this paper aftempts to clarity the policy of diplomatic missions in the UK in relation to visa applicants who report a history of mental iliness and compulsory hosplital treatment.
\end{abstract}

\section{The study}

A questionnaire was sent to the visa departments of 110 embassies, consultates and high commissions in London, representing all the diplomatic establishments which could be accessed through the Business and Services volume of the London Telephone Directory. The questionnaire addressed four areas: applicants for visitors' visas who had been detained under section 2 or section 3 and those detained under these two sections who had applied for immigration visas. The respondents were asked to ring one of five possible answers for each category and were also given an opportunity for each category to give an alternative answer of their own.

The five choices were: would you refuse a visa on the grounds of the 'section' alone, on the grounds of mental ill health alone, request further information/make further inquiries, discount this information entirely for that class of visa, or ignore it if the event occurred some time ago (how many years?). Due to a poor initial response a reminder was malled three months later.

\section{Findings}

After two mailings, 77 replies were received from 110 questionnaires. Sixty-five $(59 \%$ of the total sample) answered the questionnaire, the others sending inappropriate literature or stating that they would have to send the questionnaire to their parent country.

No differences were recorded on any questionnaire between sections 2 and 3, therefore these have been dealt with together.

Thirty-four countries (52\%) reported that they would discount any record of hospital admission under a section of the Mental Health Act, 1983 